\title{
Gender and Information Literacy: Evaluation of Gender Differences in a Student Survey of Information Sources
}

\author{
Arthur Taylor and Heather A. Dalal
}

Information literacy studies have shown that college students use a variety of information sources to perform research and commonly choose Internet sources over traditional library sources. Studies have also shown that students do not appear to understand the information quality issues concerning Internet information sources and may lack the information literacy skills to make good choices concerning the use of these sources. No studies currently provide clear guidance on how gender might influence the information literacy skills of students. Such guidance could help improve information literacy instruction.

This study used a survey of college-aged students to evaluate a subset of student information literacy skills in relation to Internet information sources. Analysis of the data collected provided strong indications of gender differences in information literacy skills. Female respondents appeared to be more discerning than males in evaluating Internet sources. Males appeared to be more confident in the credibility and accuracy of the results returned by search engines. Evaluation of other survey responses strengthened our finding of gender differentiation in information literacy skills.

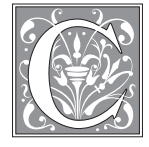

ollege students today have come of age surrounded by a sea of information delivered from an array of sources available at their fingertips at any time of the day or night. Studies have shown that the most common source of information for college-aged students is the Internet. Information gathered in this environment is most likely found using a commercial search engine that returns sources of dubious quality using an unknown algorithm. The information in this environment is often fragmented, limited in depth and breadth, disorganized, biased, of unknown authorship, and, in some cases, not credible. It is unclear whether or not students discern these deficiencies in the information they encounter.

Arthur Taylor is Associate Professor in the Department of Information Systems and Supply Chain Management, College of Business Administration, and Heather A. Dalal is Assistant Professor in the Moore Library at Rider University; e-mail: ataylor@rider.edu, hdalal@rider.edu. (C2017 Arthur Taylor and Heather A. Dalal, Attribution-NonCommercial (http://creativecommons.org/licenses/by-nc/3.0/) CC BY-NC. 
Adding to these difficulties is the self-serve nature of the Internet as an information source. Searches in a library environment (library databases) are conducted using sources that have been evaluated by information professionals. Many college students have had little or no information literacy instruction from a librarian and operate on fallacious assumptions concerning the quality of Internet information sources. A student using a self-serve approach to information resource gathering may use a commercial search engine and presume that all sources returned by that search engine are credible, though the search engine applied no such filter to the results.

Previous information literacy studies have examined the information search behavior of subjects across a limited set of information literacy skills. Not all variables affecting the review and selection of Internet information sources have been studied in detail. Specifically, it is unclear whether or not male and female students have the same level of information literacy skills. Some studies have suggested there may be gender-specific differences in media consumption and in the way each gender searches for and evaluates information sources. Determining whether or not these gender-specific differences exist in college students is important. A clear understanding of gender-specific influences could provide meaningful guidance to librarians and educators who provide information literacy training for students.

The research reported here evaluated the student perceptions of Internet information sources, specifically their evaluation of various properties or criteria of those information sources. The study used the evaluation criteria recommended in the Association of College and Research Libraries Information Literacy Competency Standard Performance Indicator 3.2a concerning "reliability, validity, accuracy, authority, timeliness, and point of view or bias" of sources. ${ }^{1}$

The terms Internet and web are commonly used interchangeably in American English. Technically, they are different as the Internet refers to a large world-wide TCP/ IP protocol network and the web is short for World Wide Web, a set of technologies, protocols, and standards that operate on a TCP/IP network using web browsers and web servers. Common English sheds this technical distinction and simply refers to the "Internet" and the "web" as the virtual place where information and applications are accessed using a web browser. When we use the term "Internet information sources" and the web in this paper, we are referring to the use of commercial search engines and the World Wide Web to access information for research. This is distinct from library databases, some of which may be available on the web.

\section{Review of Literature}

Information scientists and librarians have long been curious about student evaluation of Internet information sources. Research has shown students prefer convenience, tend to focus their research on the Internet, and will commonly use Google to search the Internet for information before using other sources. ${ }^{2}$ Some college-aged searchers demonstrate a high level of confidence in the Internet as an information source and report rarely finding incorrect information, thus perceiving no need to evaluate information sources. ${ }^{3}$ Students use the library and the Internet at different stages in their research process for coursework, typically using Wikipedia and Internet search engines first. ${ }^{4}$

Good information literacy skills require the consistent use of appropriate evaluation criteria. In a traditional library environment, the collection is curated and some evaluation criteria are applied in developing the collection. The Internet represents a very different environment where the "collection" is quite extensive but arguably of dubious quality. While this condition increases the need for application of evaluation criteria in acquisition of information sources from the Internet, constant exposure to this information environment may have created a certain complacency among those 
using it as an information source. Results from studies of students' evaluation of Internet information sources reveal an inconsistent use of criteria in evaluating Internet information sources. The Project Information Literacy study surveyed students on their frequency of using traditional evaluation criteria (currency, author's credentials, and different viewpoints expressed) and found that most students claim to evaluate Internet sources. ${ }^{5}$ Other studies, however, indicate that students are familiar with common evaluative criteria but, in practice, use these criteria far less than they claim. ${ }^{6}$ Some studies determined that, when evaluating quality or suitability of sources, students use just one or two pages or skim the content to make their decision. ${ }^{7}$ Students will also state that identifying the author of a source is important but do not consider the author's qualifications in selecting information sources. ${ }^{8}$

Lorenzen found that students had difficulty making credibility judgments on information sources without help from their instructors. ${ }^{9}$ Tillotson reported that students were aware of evaluation criteria for information sources, but their knowledge of the details of the criteria was vague and shallow. ${ }^{10}$ In some studies, students appeared to know they should not trust all websites, but they proceeded to make their credibility judgments based on questionable criteria such as the professional look of a page, level of detail in content, or lack of commercial purpose. ${ }^{11}$

Students performing research must find sources relevant to their research topic. It is therefore logical that research has shown that the criterion of "relevance" is more important than other criteria for many students. ${ }^{12}$ However, just spotting the keywords in the title or lead paragraphs may be the method used to determine relevance, ${ }^{13}$ further suggesting that students are not carefully evaluating Internet sources. Additionally, evaluating the "quality" of an information source is a critical information literacy skill. However, many college-aged researchers appear to be uninterested in evaluating the information quality and other characteristics of an information source. ${ }^{14}$

Evaluation of the credibility of a source requires subject area knowledge and context that many student researchers may lack. Research has provided some indication that students may not evaluate credibility using the best techniques. Studies have shown that many students evaluate sources based on social confirmation of credibility and use online reviews or forums that are written by an individual or group they perceive to be an enthusiast on a given topic. ${ }^{15}$ Instructors and librarians may presume students will ask them for help in evaluating sources, but student researchers appear to seek help elsewhere. One study determined that 61 percent of the respondents in their sample ask for help from friends in evaluating sources, 49 percent from instructors, and only 11 percent from librarians. ${ }^{16}$

\section{Demographic Differences in Information Searching}

Studies have provided results that indicate males and females use the Internet differently. One study found females were more likely to use the Internet more for entertainment, while men were more likely to use the Internet for news and business. ${ }^{17}$ Another study, however, found that females viewed academic websites more often and men viewed entertainment websites more regularly and preferred sites with video and sound..$^{18}$ Studies have also reported that females tend to use free resources less often and use licensed library resources more, while male students are more likely to use nontraditional online sources such as Wikipedia. ${ }^{19}$ Another study reported that women used books and journals more than men, and men used newspapers and magazines more than females. ${ }^{20}$

Some studies have also found gender differences in the perceptions of sources and confidence in their use. Lim and Kwon noted that males have higher perceptions of Wikipedia's information quality and their own ability to evaluate Wikipedia entries. ${ }^{21}$ 
Additionally, the authors examined the risk perception of subjects and reported that men perceive using Wikipedia as much less of a risk than their female classmates.

Other studies report that men are more satisfied with their results, while women are more patient and careful but report having greater uneasiness and anxiety at the beginning of their information research process. ${ }^{22}$ Studies have also reported that females appear to take a safe approach to research, while males appear to be more confident in their ability to search for information on the Internet. ${ }^{23}$

Though females may evaluate their online skills lower than males, studies report that there is no difference in the online abilities of females. ${ }^{24}$ In Burdick's research, high school females spent more time investigating and formulating topics and expressed more emotions, while males emphasized the collection of information, focused on gathering and completing faster, were less likely to ask for help, and were more confident in their search effort. ${ }^{25}$

Neely's study found women rated evaluating sources significantly more important than men. ${ }^{26}$ Kwon and Song studied both personality traits and gender in relationship to information literacy competencies and, in contrast to other studies, found that females reported a self-perception of higher competencies in the evaluation of information sources. ${ }^{27}$ Their research also found the personality trait of openness was strongly tied to females and to the skill of evaluating sources.

\section{Justification for Research}

Previous information literacy and information search process research has reported on a broad set of search behaviors for college-aged students. Most of these studies have not analyzed detailed criteria used by student searchers to select sources and have not differentiated results based on gender. Understanding specific characteristics and identifying detailed search behaviors can help librarians and instructors better prepare students to perform research. More specifically, it can help teach students to understand and evaluate the quality and usefulness of information available on the Internet.

It may be a revelation to some that gender differences in information literacy may exist. Identifying gender-specific characteristics of student information searchers will provide further clarity on how students search for information. The specifics of these gender differences can provide guidance to instructors in the preparation of genderaware information literacy instruction.

\section{Methods}

The study reported here used a survey to gather responses from subjects on how they evaluated information sources. The survey questions were based on the ACRL Information Literacy Competency Standards for Higher Education published in 2000. Questions were based primarily on Standard 3, which addresses how an informationliterate student performs critical evaluation of information sources. ${ }^{28}$ Several survey questions were used to gather background information about the subject including their college major and gender. The remaining questions asked subjects about their use of information sources and their evaluation of the reliability, validity, accuracy, authority, timeliness, and point of view or bias of Internet information sources. Most questions were specifically about Internet information sources, though a few questions asked about the use of library databases.

The survey questions were developed by the authors and then reviewed by library faculty. A pilot survey was performed using student workers in the library as subjects. Based on feedback from library faculty and the results of the pilot survey, the questions were refined to produce the final survey instrument. 
The survey was delivered in an online, web-based format, and results were stored anonymously in a database for later analysis (see figure 1). There were two groups of survey subjects: one group included students whose instructors had agreed to participate in the survey; the other group was recruited through an e-mail campaign targeted to students in the School of Education and the School of Business.

The courses where the first group of participants was recruited included multiple sections of Composition, Management, Marketing, and Organizational Leadership; many of these are taken by all students to fulfill either their major or general education requirements. Subjects in this group entered the computer lab for information literacy instruction and were presented with the online survey and an informed consent form. This form indicated how the survey would be used and that their participation was voluntary and would not affect their grade. The librarian conducting the training was available to student participants for questions if needed. Subjects did not report any difficulty or confusion with the survey questions.

The second group of survey takers was recruited through an e-mail to students in two colleges at the institution where the survey was conducted. These subjects took the survey in a remote location (not in a computer lab with faculty) at their convenience. Most survey participants were from the first group.

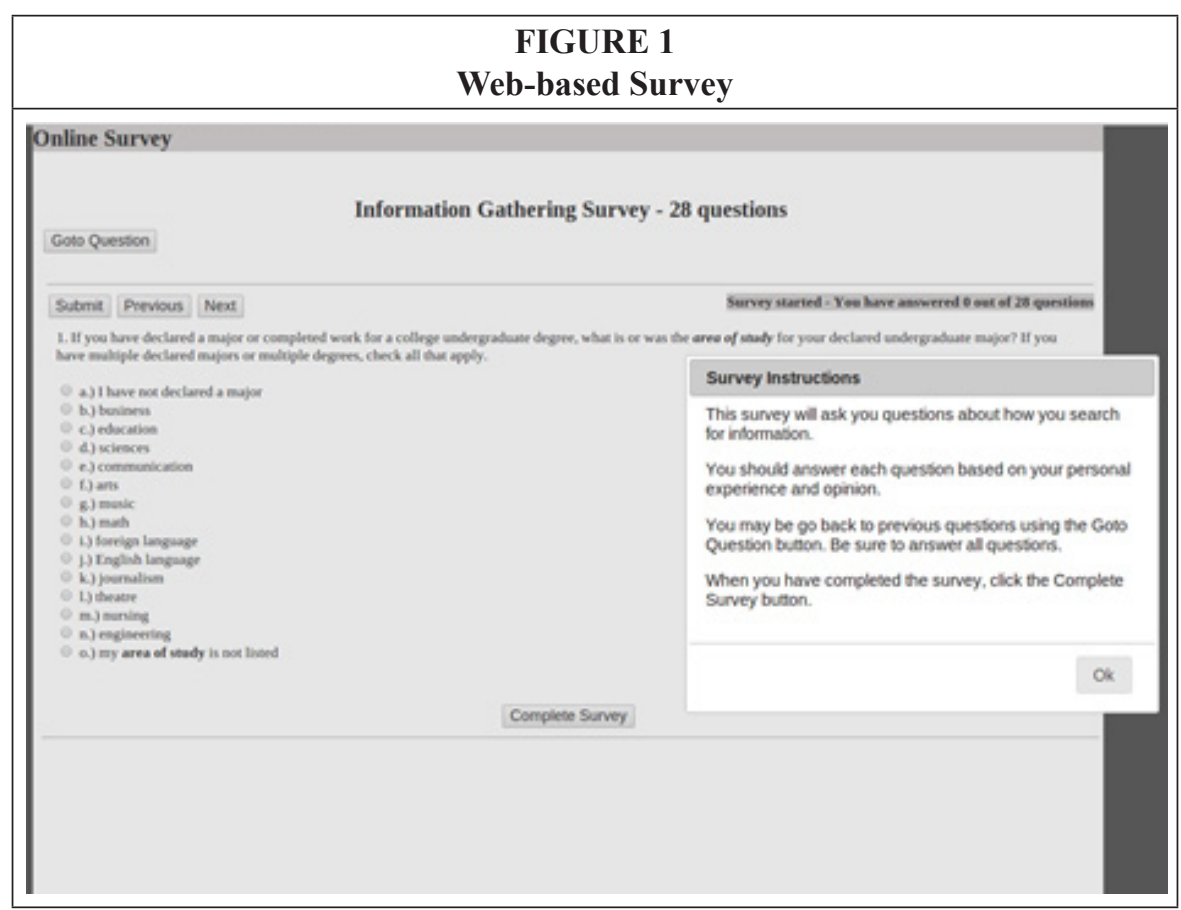

The survey contained a total of 27 questions. Subjects were directed to answer questions about how they searched for information for their college courses (college research) and how they evaluated and selected information sources. Subjects were not monitored while taking the survey and were allowed to proceed at their own pace. Subjects were not compensated for taking the survey and were informed they could stop at any time. Some subjects were optionally entered in a pool to win a $\$ 50$ gift certificate. Most subjects completed the survey in five to ten minutes. The questions relevant to this study are listed in appendix A. 


\section{Results}

A total of 386 college-aged students from an American university responded to the survey. Most survey takers completed the 27 questions in 5 to 10 minutes. The data collected was anonymous. In this survey sample, 129 respondents were male and 257 were female.

Since there were more female survey respondents than male survey respondents, there is bias in the sample toward female responses so examining raw counts of survey responses would not be useful. Instead, in-group percentages (percentages of responses to a question within a group of respondents of a gender) were used.

Chi-square analysis of variance was used to examine correlation between gender and survey responses. This result is reported where the test demonstrated a statistically significant correlation. This analysis involved running the test on the raw survey counts.

Note that for all survey questions presented in the tables that follow, the percent column is calculated as the number of respondents of a gender who selected the item divided by the total number of respondents of a gender who answered the question. Using this approach for single-select questions, the sum of the percentages for a question response will be equal to or close to 100 percent, with some deviations due to rounding errors. Using this same approach for multiple-select questions, the sum of the percentages for a question response will not total 100 percent. Questions ending in the statement "check all that apply" indicate a multiple-select question where a respondent may have selected more than one item.

\section{Analysis of Survey Responses}

Most respondents of either gender listed English as their first language (91\% of females and $88 \%$ of males). Respondents were relatively evenly distributed over years of

\section{TABLE 1}

Question: If you have declared a major or completed work for a college undergraduate degree, what is or was the area of study for your declared undergraduate major? (If you have multiple declared majors or multiple degrees, check all that apply.)

\begin{tabular}{|c|c|c|l|}
\hline Female & Male & Difference & Response \\
\hline 2.3346 & .7752 & 1.5594 & I have not declared a major \\
\hline $\mathbf{3 2 . 2 9 5 7}$ & $\mathbf{6 7 . 4 4 1 9}$ & $\mathbf{- 3 5 . 1 4 6 2}$ & business \\
\hline $\mathbf{1 9 . 0 6 6 1}$ & $\mathbf{4 . 6 5 1 2}$ & $\mathbf{1 4 . 4 1 4 9}$ & education \\
\hline 14.786 & 1.0775 & 4.7085 & sciences \\
\hline 7.393 & 3.876 & 3.517 & communication \\
\hline 4.2802 & 3.1008 & 1.1794 & arts \\
\hline 1.1673 & 2.3256 & -1.1583 & music \\
\hline 1.9455 & 2.3256 & -.3801 & math \\
\hline 1.9455 & .7752 & 1.1703 & foreign language \\
\hline 8.1712 & 2.3256 & 5.8456 & English language \\
\hline 2.3346 & .7752 & 1.5594 & journalism \\
\hline 4.2802 & 1.5504 & 2.7298 & theatre \\
\hline .7782 & & .7782 & engineering \\
\hline 17.8988 & 11.6279 & 6.2709 & my major is not listed \\
\hline
\end{tabular}


TABLE 2

Question: How often do you use the web to find information?

\begin{tabular}{|c|c|c|l|}
\hline Female & Male & Difference & Response \\
\hline $\mathbf{8 8 . 3 5}$ & $\mathbf{9 3 . 6 5}$ & $\mathbf{- 5 . 3}$ & several times a day \\
\hline 11.24 & 6.35 & 4.89 & about once a day \\
\hline .40 & & .4 & about once a week \\
\hline
\end{tabular}

matriculation: between 15 and 22 percent in each year (freshman, sophomore, junior, senior, and graduate).

Most respondents were business majors (38\%), with the remainder being a mix of liberal arts, education, and communication majors. Most subjects were female $(66 \%)$ and most subjects indicated they had a GPA of greater than $3.0(74 \%)$.

Most male respondents in this sample were business majors. Most female respondents were education majors, but female respondents were more likely to have other majors as well (see table 1). Females in the sample were more likely to have a GPA above 3.5, with 49 percent of female respondents reporting GPAs above 3.5 as opposed to 37 percent of male respondents.

When subjects were asked how often they used the web to find information, it was clear that most use the web constantly as an information source, with the majority in both genders reporting they used the web several times a day to search for information (see table 2). However, males in this sample were more likely to use the web on a daily basis, with 94 percent of the male sample using the web several times a day versus 88 percent of the female sample.

In response to a question concerning the selection of pages returned by a search engine, the females in this sample appeared to be more discerning. They were more likely to consider their ability to understand a site, and their ability to verify the information on the site, and evaluate the credentials of the author than were the male respondents. The females were also more likely to evaluate the currency of a site and the quality of the writing on the site (see table 3).

\section{TABLE 3}

Question: When a search engine returns a list of pages, I select a page from the list based on the following criteria. (Check all that apply.)

\begin{tabular}{|c|c|c|c|}
\hline Female & Male & Difference & Response \\
\hline 6.7004 & 55.814 & 4.8864 & the format of the site \\
\hline 3.1128 & 8.5271 & -5.4143 & whether or not the site has video \\
\hline 12.4514 & 13.1783 & -.7269 & the site has pictures \\
\hline 56.8093 & 51.938 & 4.8713 & the site has a lot of information \\
\hline 77.0428 & 63.5659 & 13.4769 & the site is understandable \\
\hline 22.5681 & 23.2558 & -.6877 & I am familiar with the author of the site \\
\hline 66.9261 & 58.1395 & 8.7866 & I can verify the information on the site \\
\hline 61.8677 & 41.8605 & 2.0072 & $\begin{array}{l}\text { the credentials (qualifications) of the author } \\
\text { are good }\end{array}$ \\
\hline 76.6537 & 63.5659 & 13.0878 & the site is current \\
\hline 68.4825 & 48.062 & 2.4205 & the quality of the writing on the site is good \\
\hline 22.9572 & 21.7054 & 1.2518 & there are reviews and comments on the site \\
\hline
\end{tabular}


When asked about using information sources beyond commercial search engines, females appeared to be more consistent in using other sources (see table 4). Males were much more likely to respond that they never used resources beyond Google or Ask.com (11\% for males versus $2.44 \%$ for females). Alternatively, females were more likely to respond that they almost always use information resources beyond Google or Ask.com (29.83\% for females versus $19.83 \%$ for males). The results for this question are statistically significant $(\chi$-squared $=12.299, \mathrm{df}=4, P=.01526)$.

\section{TABLE 4}

Question: Consider the papers that you have written in the last year. How often have you used research tools beyond Google or Ask.com to do your research?

\begin{tabular}{|c|c|c|l|}
\hline Female & Male & Difference & Response \\
\hline $\mathbf{2 . 4 4}$ & $\mathbf{1 0 . 7 4}$ & $\mathbf{- 8 . 3}$ & Never \\
\hline 22.69 & 23.14 & -0.45 & Infrequently-less than 25 percent of the time. \\
\hline 25.21 & 23.97 & 1.24 & Sometimes - about 50 percent of the time. \\
\hline 19.33 & 22.31 & -2.98 & Usually-about 75 percent of the time. \\
\hline $\mathbf{2 9 . 8 3}$ & $\mathbf{1 9 . 8 3}$ & $\mathbf{1 0}$ & Almost always \\
\hline
\end{tabular}

Similarly, when asked when they know they have enough sources for a paper, males were more likely to report that they do not concern themselves with the number of sources, with 13.22 percent of male respondents reporting they "don't worry about the number of sources for a paper" versus only 5.13 percent of females who chose that response (see table 5). There was an even more striking difference in the choice of the response "I try to find enough quality sources to support the information in my paper," with 83.76 percent of female respondents choosing that option versus 64.46 percent of male respondents. These results are statistically significant $(\chi$-squared $=$ 19.4695, df $=4, P<.001)$.

\section{TABLE 5}

Question: How would you know when you have enough sources for a paper?

\begin{tabular}{|c|c|c|l|}
\hline Female & Male & Difference & Response \\
\hline $\mathbf{5 . 1 3}$ & $\mathbf{1 3 . 2 2}$ & $\mathbf{- 5 . 1 3}$ & I don't worry about the number of sources for a paper. \\
\hline 8.12 & 15.70 & 7.58 & 5 sources is enough for any paper. \\
\hline 2.99 & 4.96 & 1.97 & 10 sources is enough for any paper. \\
\hline & 1.65 & 1.65 & 20 sources is enough for any paper. \\
\hline $\mathbf{8 3 . 7 6}$ & $\mathbf{6 4 . 4 6}$ & $\mathbf{- 1 9 . 3}$ & $\begin{array}{l}\text { I try to find enough quality sources to support the } \\
\text { information in my paper. }\end{array}$ \\
\hline
\end{tabular}

In response to a question about the number of search engine result pages reviewed, males were more likely to review fewer pages than females, and females were more likely to review more than 5 pages of search engine result pages (see table 6).

When asked which search engines or databases are used for research, gender differences in responses indicated stronger information literacy skills among female respondents. Males were more likely to indicate the use of Google or Yahoo! search engines for research, with 15 percent of males indicating they use Yahoo! and 87 percent indicating they use Google, versus 11 percent choosing Yahoo! and 84 percent choosing Google for female respondents. Likewise, females were more likely to select a library 


\section{TABLE 6}

Question: Consider the papers that you have written in the last year. How many pages of search engine (Google, Yahoo!, Bing) results do you usually view?

\begin{tabular}{|c|c|c|l|}
\hline Female & Male & Difference & Response \\
\hline $\mathbf{1 5 . 3 8}$ & $\mathbf{1 6 . 5 3}$ & $-\mathbf{1 . 1 5}$ & 1 page \\
\hline 32.48 & 25.62 & 6.86 & 2 pages \\
\hline $\mathbf{2 3 . 5 0}$ & $\mathbf{3 1 . 4 0}$ & $-\mathbf{7 . 9}$ & more than 2 pages \\
\hline $\mathbf{2 8 . 6 3}$ & $\mathbf{2 6 . 4 5}$ & 2.18 & more than 5 pages \\
\hline
\end{tabular}

database as a search resource (see table 7). These results are statistically significant $(\chi$-squared $=14.7654, \mathrm{df}=8, P=0.06387)$.

Female respondents also appeared to be less certain and perhaps more discerning when evaluating web sources. Male respondents indicated confidence in determining the author of a web source, with 59.50 percent of male respondents indicating it was possible to determine the author of a web page versus 52.16 percent of female respondents (see table 8). A similar distinction can be seen with the responses concerning the qualifications of the author of a web page, with 32.23 percent of male respondents indicating they could determine the qualifications of the author of a web page versus 28.33 percent of female respondents (see table 9).

\section{TABLE 7}

Question: Which search engines or library databases do you use for your research? Check all that apply.

\begin{tabular}{|c|c|c|l|}
\hline Female & Male & Difference & Response \\
\hline $\mathbf{1 0 . 5 0 5 8}$ & $\mathbf{1 4 . 7 2 8 7}$ & $\mathbf{- 4 . 2 2 2 9}$ & Yahoo! \\
\hline 9.3385 & 9.3023 & .0362 & Bing \\
\hline $\mathbf{8 3 . 6 5 7 6}$ & $\mathbf{8 7 . 5 9 6 9}$ & $\mathbf{- 3 . 9 3 9 3}$ & Google \\
\hline 4.2802 & 4.6512 & -0.371 & Other Search engine such as: Blekko/Lycos/AOL \\
\hline & & & $\begin{array}{l}\text { Metasearch engine (one that cross-searches other } \\
\text { search engines) such as Ixquick/Dogpile/Clusty/ } \\
\text { Webcrawler/Mywebsearch }\end{array}$ \\
\hline $\mathbf{7 3 . 1 5 1 8}$ & $\mathbf{5 8 . 1 3 9 5}$ & $\mathbf{1 5 . 0 1 2 3}$ & $\begin{array}{l}\text { Premier/CQ Researcher/Credo Reference/LexisNexis/ } \\
\text { JSTOR/Omnifile/Gale Virtual Reference /Ebscohost }\end{array}$ \\
\hline $\mathbf{4 3 . 1 9 0 7}$ & $\mathbf{3 3 . 3 3 3 3}$ & $\mathbf{9 . 8 5 7 4}$ & $\begin{array}{l}\text { Subject-specific library databases such as: ABI-Infom, } \\
\text { ArtStor, Business Source Premier, Communication }\end{array}$ \\
\hline $\mathbf{3 4 . 6 3 0 4}$ & $\mathbf{1 9 . 3 7 9 8}$ & $\mathbf{1 5 . 2 5 0 6}$ & $\begin{array}{l}\text { Library OneSearch (cross-searches the library catalog } \\
\text { and most of our databases) }\end{array}$ \\
\hline $\mathbf{2 8 . 0 1 5 6}$ & $\mathbf{1 3 . 9 5 3 5}$ & $\mathbf{1 4 . 0 6 2 1}$ & Library Book Catalog \\
\hline
\end{tabular}

\section{TABLE 8}

Question: It is usually possible to determine the author of a web page.

\begin{tabular}{|c|c|c|l|}
\hline Female & Male & Difference & Response \\
\hline $\mathbf{5 2 . 1 6}$ & $\mathbf{5 9 . 5 0}$ & $-\mathbf{7 . 3 4}$ & TRUE \\
\hline $\mathbf{4 7 . 8 4}$ & $\mathbf{4 0 . 5 0}$ & $\mathbf{7 . 3 4}$ & FALSE \\
\hline
\end{tabular}




\section{TABLE 9}

Question: It is usually possible to determine the qualifications of the author of a web page.

\begin{tabular}{|c|c|c|l|}
\hline Female & Male & Difference & Response \\
\hline $\mathbf{2 8 . 3 3}$ & $\mathbf{3 2 . 2 3}$ & $\mathbf{- 3 . 9}$ & TRUE \\
\hline $\mathbf{6 6 . 0 9}$ & $\mathbf{5 9 . 5 0}$ & $\mathbf{6 . 5 9}$ & FALSE \\
\hline & & -2.68 & $\begin{array}{l}\text { I do not understand what is meant by } \\
\text { qualifications in this question }\end{array}$ \\
\hline
\end{tabular}

A notably deep distinction exists between gender perceptions concerning general trust or mistrust of search engine results. Most male respondents in this sample $(71.43 \%)$ indicated that they believed search engine results usually contain accurate information, whereas 55.17 percent of female respondents indicated that was the case (see table 10). These results are statistically significant ( $\chi$-squared $=4.5126, \mathrm{df}=1, P=0.03365)$.

In evaluating the objectiveness of a source, males were more likely to trust their search engine to return objective pages and were also more likely to indicate that they do not evaluate the objectiveness of a site, consistent with their other responses

\section{TABLE 10}

Question: I believe the pages listed by a search engine results usually contain accurate information.

\begin{tabular}{|c|c|c|l|}
\hline Female & Male & Difference & Response \\
\hline $\mathbf{5 5 . 1 7}$ & $\mathbf{7 1 . 4 3}$ & $\mathbf{- 1 6 . 2 6}$ & TRUE \\
\hline $\mathbf{4 4 . 8 3}$ & $\mathbf{2 8 . 5 7}$ & $\mathbf{1 6 . 2 6}$ & FALSE \\
\hline
\end{tabular}

\section{TABLE 11}

Question: How do you decide whether or not a source retrieved from the Internet is objective and provides fair and equal treatment of all sides of a topic? (Check all that apply.)

\begin{tabular}{|c|c|c|c|}
\hline Female & Male & Difference & Response \\
\hline 1.5564 & 3.1008 & -1.5444 & $\begin{array}{l}\text { I do not understand what is meant by "objective" in this } \\
\text { question. }\end{array}$ \\
\hline 6.2257 & $\mathbf{1 0 . 8 5 2 7}$ & -4.627 & $\begin{array}{l}\text { I believe that pages returned by my search engine are } \\
\text { objective. }\end{array}$ \\
\hline 67.7043 & 57.3643 & 10.34 & $\begin{array}{l}\text { I look at the URL of the site, and based on the domain } \\
\text { (.com, .edu, .org, .net, etc.) and use that information to } \\
\text { help me determine whether or not the site is objective. }\end{array}$ \\
\hline 25.6809 & 24.8062 & 0.8747 & $\begin{array}{l}\text { I check with someone who may know; for example, } \\
\text { library staff or a professor. }\end{array}$ \\
\hline 6.2257 & 10.8527 & -4.627 & I ask a friend if he or she thinks the site is objective. \\
\hline 72.7626 & 65.1163 & 7.6463 & $\begin{array}{l}\text { If the document provides a fair discussion of all sides } \\
\text { of a topic or issue and acknowledges other viewpoints, } \\
\text { then I consider it objective. }\end{array}$ \\
\hline 5.0584 & 10.8527 & -5.7943 & I do not evaluate the objectiveness of a site. \\
\hline 5.0584 & 6.2016 & -1.1432 & $\begin{array}{l}\text { I do not believe it is possible to determine the } \\
\text { objectiveness of a page returned by a search engine. }\end{array}$ \\
\hline
\end{tabular}




\section{TABLE 12}

Question: How do you decide whether or not information on a page is accurate and contains truthful and correct information? Check all that apply.

\begin{tabular}{|c|c|c|l|}
\hline Female & Male & Difference & Response \\
\hline 1.9455 & 2.3256 & -.3801 & $\begin{array}{l}\text { I do not understand what is meant by "accurate" in } \\
\text { this question. }\end{array}$ \\
\hline $\mathbf{2 . 7 2 3 7}$ & $\mathbf{1 3 . 1 7 8 3}$ & $\mathbf{- 1 0 . 4 5 4 6}$ & $\begin{array}{l}\text { I believe that pages returned by my search engine are } \\
\text { accurate. }\end{array}$ \\
\hline $\mathbf{6 6 . 1 4 7 9}$ & $\mathbf{5 4 . 2 6 3 6}$ & $\mathbf{1 1 . 8 8 4 3}$ & $\begin{array}{l}\text { I look at the URL of the site, and based on the } \\
\text { domain (.com, .edu, .org, .net, etc.) and use that } \\
\text { information to help me determine whether or not the } \\
\text { site is accurate. }\end{array}$ \\
\hline 36.1868 & 31.7829 & 4.4039 & $\begin{array}{l}\text { I check with someone with knowledge of the site or } \\
\text { topic; for example, library staff or a professor. }\end{array}$ \\
\hline 31.5175 & 29.4574 & 2.0601 & $\begin{array}{l}\text { I believe that sites with a more current date are more } \\
\text { accurate. }\end{array}$ \\
\hline 4.6693 & 5.4264 & -.7571 & $\begin{array}{l}\text { I do not check the accuracy of information on a Web } \\
\text { site. }\end{array}$ \\
\hline
\end{tabular}

concerning their use of search engines (see table 11). Males were also more likely to ask a friend if a site is objective. Female respondents indicated that they were more likely to examine the URL of a site and to consider the content of the document to evaluate objectiveness. These results are statistically significant $(\chi$-squared $=12.238$, $\mathrm{df}=7, P=0.093$ ).

Consistent with response results on other questions, male respondents in this survey were more likely to trust the pages returned by their search engine, with 13 percent of males indicating that they believed pages returned by their search engine were accurate versus 3 percent of females (see table 12). Females were also more likely to use the URL of the site to evaluate accuracy, with 66 percent of females indicating they used the URL to evaluate accuracy versus 54 percent of males. These results are statistically significant $(\chi$-squared $=17.8213, \mathrm{df}=5, P=0.003179$ ).

When asked how they evaluate the credibility of a site, female respondents were once again more likely to use the URL to determine the credibility of a site, with 63 percent of female respondents choosing that option versus 51 percent of male respondents (see table 13). Females were also more likely to examine who published the site, with 63 percent of females indicating that they examine the site publisher versus 53 percent of males. Males continue to indicate a strong degree of trust in the search engine, with 16 percent of male respondents indicating the pages returned by their search engine are credible versus 5 percent of female respondents. These results are statistically significant $(\chi$-squared $=19.1975, \mathrm{df}=7, P=0.007591$ ).

When asked a question about how to evaluate the quality of a page returned by a search engine, female subjects once again indicated the URL was significant to them, with 58 percent of female respondents indicating they use the URL and domain to determine whether or not a site is a quality site versus 42 percent of male respondents (see table 14). Females also indicated they were more likely to ask a professor or someone with knowledge of the site for guidance, with 19 percent of females indicating they would check with someone knowledgeable about a site versus 12 percent of males. These results are statistically significant $(\chi$-squared $=$ 43.7426, $\mathrm{df}=1, P<.001)$. 


\section{TABLE 13}

Question: How would you evaluate the credibility of a site or document and determine that the information is truthful and trustworthy? Check all that apply.

\begin{tabular}{|c|c|c|l|}
\hline Female & Male & Difference & Response \\
\hline 1.5564 & 3.876 & -2.3196 & $\begin{array}{l}\text { I do not understand what is meant by "credibility" in } \\
\text { this question. }\end{array}$ \\
\hline $\mathbf{6 3 . 0 3 5}$ & $\mathbf{5 1 . 1 6 2 8}$ & $\mathbf{1 1 . 8 7 2 2}$ & $\begin{array}{l}\text { I look at the URL of the site, and based on the domain } \\
\text { help me determine whether or not the site is credible. }\end{array}$ \\
\hline 56.8093 & 56.5891 & $\mathbf{. 2 2 0 2}$ & $\begin{array}{l}\text { I look at the background of the author of the page- } \\
\text { else he or she has written. }\end{array}$ \\
\hline $\mathbf{6 2 . 6 4 5 9}$ & $\mathbf{5 2 . 7 1 3 2}$ & $\mathbf{9 . 9 3 2 7}$ & I check to see who published the information on the site. \\
\hline $\mathbf{5 . 0 5 8 4}$ & $\mathbf{1 6 . 2 7 9 1}$ & $-\mathbf{1 1 . 2 2 0 7}$ & $\begin{array}{l}\text { I believe that pages returned by my search engine are } \\
\text { credible. }\end{array}$ \\
\hline 3.8911 & 6.2016 & -2.3105 & I do not evaluate the credibility of websites. \\
\hline 5.8366 & 4.6512 & 1.1854 & $\begin{array}{l}\text { I do not believe it is possible to evaluate the credibility } \\
\text { of pages returned by a search engine. }\end{array}$ \\
\hline 35.7977 & 38.7597 & -2.962 & $\begin{array}{l}\text { I evaluate the information on the site against what I } \\
\text { know about the topic. }\end{array}$ \\
\hline
\end{tabular}

\section{TABLE 14}

Question: How do you evaluate the quality of a page returned by a search engine? Check all that apply

\begin{tabular}{|c|c|c|l|}
\hline Female & Male & Difference & Response \\
\hline 2.3346 & 5.4264 & -3.0918 & $\begin{array}{l}\text { I do not understand what is meant by "quality" in this } \\
\text { question. }\end{array}$ \\
\hline 11.284 & 10.8527 & .4313 & If the page includes pictures and charts, it is a quality site. \\
\hline 53.6965 & 48.8372 & 4.8593 & $\begin{array}{l}\text { If the page is free from incorrect spelling, typographical } \\
\text { errors, and poor grammar, I consider it a quality site. }\end{array}$ \\
\hline $\mathbf{7 0 . 8 1 7 1}$ & $\mathbf{6 2 . 7 9 0 7}$ & $\mathbf{8 . 0 2 6 4}$ & $\begin{array}{l}\text { If the information presented in the site is comprehensive } \\
\text { and covers the topic is considerable depth, I consider it }\end{array}$ \\
\hline $\mathbf{5 7 . 5 8 7 5}$ & $\mathbf{4 1 . 8 6 0 5}$ & $\mathbf{1 5 . 7 2 7}$ & $\begin{array}{l}\text { I look at the URL of the site, and based on the domain } \\
\text { help me determine whether or not the site is a quality site. }\end{array}$ \\
\hline 2.3346 & 3.876 & -1.5414 & $\begin{array}{l}\text { I do not evaluate the quality of pages returned by a } \\
\text { search engine. }\end{array}$ \\
\hline $\mathbf{3 7 . 7 4 3 2}$ & $\mathbf{4 3 . 4 1 0 9}$ & $\mathbf{- 5 . 6 6 7 7}$ & $\begin{array}{l}\text { If the information on the page is interesting and presents } \\
\text { a clear, well-reasoned explanation of the topic, I } \\
\text { consider it a quality page. }\end{array}$ \\
\hline 3.1128 & 1.5504 & 1.5624 & $\begin{array}{l}\text { I do not believe it is possible to determine the quality of } \\
\text { a page returned by a search engine. }\end{array}$ \\
\hline $\mathbf{1 8 . 6 7 7}$ & $\mathbf{1 1 . 6 2 7 9}$ & $\mathbf{7 . 0 4 9 1}$ & $\begin{array}{l}\text { I check with someone with knowledge of the site or } \\
\text { topic; for example, library staff or a professor. }\end{array}$ \\
\hline
\end{tabular}




\section{TABLE 15}

Question: How do you evaluate the authority of a page and determine the ability to comment or write about a particular topic? (Check all that apply.)

\begin{tabular}{|c|c|c|l|}
\hline Female & Male & Difference & Response \\
\hline $\mathbf{1 5 . 9 5 3 3}$ & $\mathbf{2 0 . 9 3 0 2}$ & -4.9769 & $\begin{array}{l}\text { I do not understand what is meant by "authority" in } \\
\text { this question. }\end{array}$ \\
\hline 44.7471 & 42.6357 & 2.1114 & $\begin{array}{l}\text { I do not believe it is possible to determine the authority } \\
\text { of a page returned by a search engine. }\end{array}$ \\
\hline other pages, articles, or books about the topic.
\end{tabular}

When asked how they evaluate the authority of a page, 20 percent of male respondents indicated that they did not understand what was meant by authority in the question versus 16 percent of female respondents (see table 15). Twelve (12) percent of male respondents indicated that they did not believe it was possible to determine the authority of a page returned by a search engine versus 3 percent of female respondents.

\section{TABLE 16}

Question: How do you evaluate the currency of a page and determine how current the information on the site is? Check all that apply.

\begin{tabular}{|c|c|c|l|}
\hline Female & Male & Difference & Response \\
\hline $\mathbf{5 . 8 3 6 6}$ & $\mathbf{1 3 . 1 7 8 3}$ & $-\mathbf{7 . 3 4 1 7}$ & $\begin{array}{l}\text { I do not understand what is meant by "currency" in this } \\
\text { question. }\end{array}$ \\
\hline $\mathbf{3 8 . 1 3 2 3}$ & $\mathbf{2 7 . 9 0 7}$ & $\mathbf{1 0 . 2 2 5 3}$ & I examine how frequently the site has been updated. \\
\hline $\mathbf{5 6 . 8 0 9 3}$ & $\mathbf{4 2 . 6 3 5 7}$ & $\mathbf{1 4 . 1 7 3 6}$ & I look for a date on the site. \\
\hline 1.5564 & 3.1008 & -1.5444 & $\begin{array}{l}\text { I do not believe it is possible to determine if the } \\
\text { information returned by a search engine is current. }\end{array}$ \\
\hline 2.7237 & 5.4264 & -2.7027 & I do not evaluate the currency of a site. \\
\hline 6.2257 & 11.6279 & -5.4022 & $\begin{array}{l}\text { I check with someone with knowledge of the site or } \\
\text { topic; for example, library staff or a professor. }\end{array}$ \\
\hline 40.4669 & 25.5814 & 14.8855 & I look for a copyright date. \\
\hline 35.4086 & 31.7829 & 3.6257 & I look at the dates of the references. \\
\hline $\mathbf{2 4 . 5 1 3 6}$ & $\mathbf{1 1 . 6 2 7 9}$ & $\mathbf{1 2 . 8 8 5 7}$ & $\begin{array}{l}\text { I check to see if all the links are still active (broken links } \\
\text { will lead me to believe the site is not current). }\end{array}$ \\
\hline
\end{tabular}




\section{TABLE 17}

Question: How do you evaluate the purpose or bias of a Web site? Check all that apply.

\begin{tabular}{|l|c|c|l|}
\hline Female & Male & Difference & Response \\
\hline $\mathbf{4 . 6 6 9 3}$ & $\mathbf{8 . 5 2 7 1}$ & $\mathbf{- 3 . 8 5 7 8}$ & $\begin{array}{l}\text { I do not understand what is meant by "purpose" in this } \\
\text { question. }\end{array}$ \\
\hline 46.6926 & 44.186 & 2.5066 & $\begin{array}{l}\text { I determine whether or not the author of the page or } \\
\text { the owner of the URL is trying to sell something. }\end{array}$ \\
\hline $\mathbf{6 8 . 4 8 2 5}$ & $\mathbf{5 7 . 3 6 4 3}$ & $\mathbf{1 1 . 1 1 8 2}$ & $\begin{array}{l}\text { I examine whether or not the purpose of the site is to } \\
\text { promote a particular opinion or point of view }\end{array}$ \\
\hline 48.6381 & 48.8372 & -.1991 & I examine whether or not the site is spam, hoax, or joke. \\
\hline 9.7276 & 9.3023 & .4253 & I do not evaluate the purpose of a site. \\
\hline $\mathbf{1 . 9 4 5 5}$ & $\mathbf{4 . 6 5 1 2}$ & $-\mathbf{- 2 . 7 0 5 7}$ & $\begin{array}{l}\text { I do not believe it is possible to determine the purpose } \\
\text { of a page returned by a search engine. }\end{array}$ \\
\hline 12.0623 & 12.4031 & -0.3408 & $\begin{array}{l}\text { I check with someone with knowledge of the site or } \\
\text { topic, for example, library staff or a professor. }\end{array}$ \\
\hline
\end{tabular}

Females were more likely to review the qualifications and prior work of the author of a page to determine the authority of a page, 47 percent of female respondents versus 40 percent of male respondents. Females were also more likely to use the URL to determine the authority of a page. These results are statistically significant $(\chi$-squared $=$ 16.6788, $\mathrm{df}=6, P=0.01054$ ).

When asked about evaluating the currency of a page, males were more likely to respond that they did not understand what currency meant in the question $(13 \%$ of males versus $6 \%$ of females). Females were more likely to provide a number of answers that indicated they were evaluating currency (see table 16). These results are statistically significant $(\chi$-squared $=25.4271, \mathrm{df}=8, P=0.001315$ ).

When asked how they determine the purpose or bias of a website, male respondents were more likely to indicate that they did not understand what was meant by the question: 9 percent male versus 5 percent female (see table 17). Female respondents were more likely to report evaluation of characteristics of the site to determine bias, with 69 percent of females indicating that they examined whether the purpose of a site is to promote an opinion or point of view versus 57 percent of male respondents.

\section{Summary of Results}

The responses to the survey questions from both genders reveal a mixture of what would be considered good IL skills and what would be considered questionable or problematic IL skills. In analyzing these based on variations in percentages and analysis of variance for raw counts, we found some very clear indications of gender bias in the information literacy skills of college students. Major findings based on the analysis of the data collected in this study are as follows:

- Based on statistically significant results, females in this sample appeared to be more discerning in evaluating a site or source and used a number of criteria in evaluating the source.

- Statistically significant results indicated that females in this sample were more likely to use critical evaluation criteria such as their ability to understand a site, their ability to verify the information on the site, and the ability to evaluate the credentials of the author. Female respondents were also more likely to evaluate the currency of a site and the quality of the writing on the site. 
- Statistically significant results indicated that females in this sample were more likely to use sources beyond Google or Ask.com and more likely to use library databases.

- Statistically significant results indicated that females in this sample were more likely to try to find enough quality sources to support the information in their paper and males reported being less concerned with the number of sources in a paper.

- Statistically significant results indicated that females were more likely to evaluate the quality of the site using the URL or were willing to check with someone with knowledge about the quality of the site.

- Males in this sample appeared to be more confident that they could determine the author of a web page and the qualifications of the author of a web page.

- Statistically significant results indicated that males in this sample believed the pages returned by their search engine were accurate and credible.

- Statistically significant results indicated that males in this sample were more likely to believe that the pages listed by a search engine usually contained accurate information.

- Statistically significant results indicated that males in this sample were more likely to believe an Internet source was objective and were also more likely to ignore the objectiveness of the site.

- Statistically significant results indicated that males in this sample were more likely to be confused about the criteria of source currency, and females were more likely to provide a number of answers that indicated they were evaluating source currency.

\section{Discussion}

Information literacy skill involves the selection of information sources using various criteria as part of an information search process. As indicated previously, analysis of seventeen questions in our survey of evaluation criteria found consistent evidence of gender-specific variations for student use and understanding of these criteria. Specifically, our analysis indicated that female respondents were more likely to evaluate the currency of a site and the quality of the writing on the site and were more likely to evaluate the quality of the site using the URL or were willing to check with someone with knowledge about the quality of the site. These results add to our impression of the careful female researcher, providing further evidence that the female subjects were concerned with finding valid, credible sources to strengthen their research projects. This validates and extends Neely's finding that women consider evaluating sources to be more important than men do and demonstrate the self-efficacy to apply evaluative criteria. ${ }^{29}$

Additional evidence that females are more careful searchers is supported by our finding that the females in our sample were more likely to use sources beyond commercial search engines and more likely to use library resources. This supports and extends previous research that found females were more likely to use books and journals than men do. ${ }^{30}$

Burdick worked with high school students and made the observation that females were more reflective. ${ }^{31}$ The sources available on the Internet have changed significantly since 1995 when Burdick's study was completed. Our results are based on a study of college-aged students conducted in 2013. It is intriguing that, given the differences in time (over 18 years of Internet information growth) and the age of the subject pools, this study continues to find similar gender-specific differences. It could be that females are socialized in a way to make more effort in their schoolwork and craft their 
arguments accordingly. Some studies have provided evidence that parents encourage female children with schoolwork more than they do male children, and young male academic performance may be hindered by their assumption that adults believe girls are better students than boys are. ${ }^{32}$

We do not believe our results necessarily indicate that males are unconcerned with the quality of their research. In fact, across the responses to several questions the majority of males reported what would be considered good IL skills. But more males were likely to choose responses indicating questionable IL skills, and in response to several questions, they did so with a statistically significant amount of responses. It could be that male students did not feel the need to use some evaluation criteria since they believe pages returned by a search engine are objective, credible, and accurate. Males in our sample consistently expressed confidence in their information evaluation skills and about the quality of results from the search engines they were using. They also reported being less concerned with the number of sources in a paper. Results of other studies report similar confident behavior from male subjects. ${ }^{33}$

That males are confident in search engine results is clear, but this could be an indication that males are exhibiting satisficing behavior, choosing the easiest path to the selection of sources. Their stated confidence in the quality of search engine results could simply be reinforcement of this behavior. ${ }^{34}$ Other studies have reported similar issues with convenience as a factor in information searches of students of both genders. ${ }^{35}$

\section{Limitations}

These results were based on a sample composed primarily of undergraduate students at an American university. This limits the generalizability of these results. A sample drawn from a broader mix of cultures and grade levels and including more graduate students might produce different results.

Subjects took our survey before they received information literacy instruction from library faculty at our institution. Some subjects may have had information literacy instruction in a class or at another institution before taking our survey.

We did not conduct a reliability and validity test on the questions in this survey. Our survey questions were used to collect demographic and background data where validity is not an issue (for example, gender, year in college) or for subjects to report evaluation and use of information sources. A validity test is used to determine the accuracy of a question to test an effect. Our questions were not used to test an effect per se; instead, they were used to have the subject self-report past behaviors (use of information sources). While we believe our questions were clear and the data gathered were valid reports of the subject's past behavior, a validity test could have been used to further refine the questions.

More males in this study were business majors, so results could be associated with the student's choice of major. A subset of females in our sample reported higher GPAs above 3.5 (49\% of females versus $37 \%$ of males). Our results could also be an indication that students with higher GPAs exhibit these search behaviors. Likewise, gender could be an influence on the selection of a major.

\section{Implication of Findings}

The results presented here raise questions concerning the appropriateness of current information literacy instruction. Librarians often stress the use of evaluation criteria but, given constraints on time available and staffing, may not have the opportunity to explore with students how to apply the criteria. If males and females appear to be using a different approach to source selection, then the approach used by each must be considered and any deficiencies addressed. This does not imply different information 
literacy instruction for males and females (not a realistic possibility at most institutions), but it could be that specific issues identified by this research for both genders becomes part of a coeducational and gender-aware approach to information literacy instruction, as a part of librarians' efforts to meet the needs of all learners.

Librarians often provide individual instruction sessions, both at the reference desk and in consultations in their offices. Our research has informed us that females are more concerned with evaluating sources, and, like Burdick's suggestion, educators should be mindful that females who express concern with their research require more "encouragement to take intellectual risks" and "reassurance that they are capable." 36 Fields suggests college-aged women's information literacy skills can be further developed by focusing on connections, collaborations, and firsthand experiences. ${ }^{37}$ The author describes specific areas where women feel "held back": for example, women have the ability to, but are uncomfortable with, constructing arguments and expressing their own opinions, especially at younger ages. ${ }^{38}$ The author suggests that this is a part of a student's intellectual development toward the path of having her own "voice" or own authority and helps her to use information to create new knowledge. ${ }^{39}$

This voice finding is essential for the intellectual and professional development of women. Kay and Shipman describe women's "acute lack of confidence" and a reluctance to take risks as the underlying reason women have so rarely risen into senior management. ${ }^{40}$ Thus, it is not hard to believe that a female at any age would have less confidence and spend more time evaluating a source that she might use for an argumentative research project. Encouraging instructors and librarians to recognize gender-specific information literacy traits could give female students skills to increase their research self-efficacy and thus increase their likeliness for success.

Male college students appear to express confidence in the quality of Internet information sources, but in reality this confidence may be misplaced. Male college students must learn the importance of being more discerning where Internet information sources are concerned. This would involve information literacy instruction that stresses the limitations of commercial search engines and the need for careful evaluation of Internet information sources using a variety of criteria. Given that male students appear to be more confused by some evaluation criteria (currency, authority), additional instruction should focus on the meaning of these criteria and the process for proper evaluation of sources using these criteria.

Our research confirms and extends findings on library anxiety, the anxious feeling surrounding information research. ${ }^{41}$ Research by Blundell and Lambert found a significant difference in library anxiety expressed by their male and female respondents. Males were more comfortable using the library and females experienced more confusion navigating library resources. Males believed instructions for using the computers were helpful, whereas female respondents perceived reference librarians as unhelpful. ${ }^{42}$ If females are more discerning in the evaluation of information sources, then it is logical that they would be more anxious or confused about using library resources. Perhaps female feelings of anxiety motivate them to evaluate information resources more thoroughly, or perhaps males are less concerned with evaluating information sources because they have more confidence in all their sources.

\section{Directions for Future Research}

Student researchers must evaluate information sources using various criteria. Previous information literacy instruction recognized and identified these criteria often in the form of a checklist. But research has suggested that, in practice, students struggle with the actual use of these evaluation criteria. ${ }^{43}$ Part of the difficulty has been attributed to the changing information environment, which includes the Internet and the increasing 
availability of mobile devices with information-gathering capabilities. In recognition of these difficulties and the ever-changing global information environment, the ACRL Information Literacy Competency Standards for Higher Education have been replaced by a "Framework for Information Literacy." 44 This new framework emphasizes information literacy instruction that encourages students to recognize their own authority in the context of information gathering.

The use of a framework approach does partly address the dynamics of information gathering in today's culture, but it also increases the responsibility and difficulty for the student in evaluating information sources. Teaching students information literacy skills within this new framework requires a clear understanding of both the student (his or her characteristics) and the individual's information search process.

The research reported here identified gender-specific distinctions in information literacy skills in a sample of undergraduate and graduate students at an American institution of higher education. Future research should examine other population samples and attempt to determine if other student characteristics might influence students' information literacy skills, specifically in relation to the use of Internet information sources.

\section{Conclusion}

Our research has suggested that college-aged students of both genders have issues evaluating information resources. Developing good information literacy skills is becoming increasingly important in a world permeated with commercialized media. Students must question information sources and develop skills for applying important evaluation criteria such as quality, credibility, bias, and validity. These skills are important not only in the pursuit of their careers but in supporting their role as informed citizens in a participatory democracy.

Whether it is desirable or not, it is reasonable to expect that the use of the Internet as an information source for college students will continue and will likely increase. Information literacy instruction should recognize the distinct characteristics of college students that might affect their information literacy skills, specifically the genderspecific characteristics that this research identified. 


\section{APPENDIX A: Survey Questions}

If you have declared a major or completed work for a college undergraduate degree, what is or was the area of study for your declared undergraduate major? If you have multiple declared majors or multiple degrees, check all that apply

- I have not declared a major

- business

- education

- sciences

- communication

- arts

- music

- math

- foreign language

- English language

- journalism

- theatre

- $\quad$ engineering

- $\quad$ my major is not listed

How often do you use the web to find information?

- several times a day

- about once a day

- about once a week

When a search engine returns a list of pages, I select a page from the list based on the following criteria. Check all that apply.

- the format of the site

- whether or not the site has video

- the site has pictures

- the site has a lot of information

- the site is understandable

- I am familiar with the author of the site

- I can verify the information on the site

- the credentials (qualifications) of the author are good

- the site is current

- the quality of the writing on the site is good

- there are reviews and comments on the site

Consider the papers that you have written in the last year. How often have you used research tools beyond Google or Ask.com to do your research?

- Never

- Infrequently; less than 25 percent of the time

- Sometimes; about 50 percent of the time

- Usually; about 75 percent of the time

- Almost always

How would you know when you have enough sources for a paper?

- I don't worry about the number of sources for a paper

- 5 sources is enough for any paper

- 10 sources is enough for any paper

- 20 sources is enough for any paper

- I try to find enough quality sources to support the information in my paper 
Consider the papers that you have written in the last year. How many pages of search engine (Google, Yahoo!, Bing) results do you usually view?

- 1 page

- 2 pages

- $\quad$ more than 2 pages

- $\quad$ more than 5 pages

Which search engines or library databases do you use for your research? Check all that apply.

- Yahoo!

- $\quad$ Bing

- Google

- Another search engine such as: Blekko/Lycos/AOL

- Metasearch engine (one that cross-searches other search engines) such as Ixquick/Dogpile/Clusty/Webcrawler/Mywebsearch

- General library databases such as Academic Search Premier/CQ Researcher/ Credo Reference/LexisNexis/JSTOR/Omnifile/Gale Virtual Reference/Ebscohost

- Subject-specific library databases such as ABI-Infom, ArtStor, Business Source Premier, Communication

- Library OneSearch (cross-searches the library catalog and most of our databases)

- Library book catalog

It is usually possible to determine the author of a web page.

- True

- False

It is usually possible to determine the qualifications of the author of a web page.

- True

- $\quad$ False

I believe the pages listed by a search engine results usually contain accurate information.

- True

- False

How do you decide whether or not a source retrieved from the Internet is objective and provides fair and equal treatment of all sides of a topic? Check all that apply.

- I do not understand what is meant by objective in this question

- I believe that pages returned by my search engine are objective

- I look at the URL of the site and, based on the domain (.com, .edu, .org, net, or others), use that information to help me determine whether or not the site is objective

- I check with someone who may know (for example, library staff or a professor)

- I ask a friend if he or she thinks the site is objective

- If the document provides a fair discussion of all sides of a topic or issue and acknowledges other viewpoints, then I consider it objective

- I do not evaluate the objectiveness of a site

- I do not believe it is possible to determine the objectiveness of a page returned by a search engine

How do you decide whether or not information on a page is accurate and contains truthful and correct information? Check all that apply. 
- I do not understand what is meant by accurate in this question

- I believe that pages returned by my search engine are accurate

- I look at the URL of the site, based on the domain (.com, .edu, .org, .net, or others), use that information to help me determine whether or not the site is accurate

- I check with someone with knowledge of the site or topic (for example, library staff or a professor)

- I believe that sites with a more current date are more accurate

- I do not check the accuracy of information on a website

How would you evaluate the credibility of a site or document and determine that the information is truthful and trustworthy? Check all that apply.

- I do not understand what is meant by credibility in this question

- I look at the URL of the site and, based on the domain (.com, .edu, .org, net, or others), use that information to help me determine whether or not the site is credible

- I look at the background of the author of the page: professional affiliations, college degrees, other writings

- I check to see who published the information on the site

- I believe that pages returned by my search engine are credible

- I do not evaluate the credibility of websites

- I do not believe it is possible to evaluate the credibility of pages returned by a search engine

- I evaluate the information on the site against what I know about the topic

How do you evaluate the quality of a page returned by a search engine? Check all that apply.

- I do not understand what is meant by quality in this question

- If the page includes pictures and charts, it is a quality site

- If the page is free from spelling and typographical errors and the author uses good grammar, I consider it a quality site

- If the information presented in the site is comprehensive and covers the topic in considerable depth, I consider it a quality site

- I look at the URL of the site and, based on the domain (.com, .edu, .org, net, or others), use that information to help me determine whether or not the site is a quality site

- I do not evaluate the quality of pages returned by a search engine

- If the information on the page is interesting, and presents a clear, well-reasoned explanation of the topic, I consider it a quality page

- I do not believe it is possible to determine the quality of a page returned by a search engine

- I check with someone with knowledge of the site or topic (for example, library staff or a professor)

How do you evaluate the authority of a page and determine the ability to comment or write about a particular topic? Check all that apply.

- I do not understand what is meant by authority in this question

- I do not believe it is possible to determine the authority of a page returned by a search engine

- I check to see if the author of the page has published other pages, articles, or books about the topic

- I look for information about the author of the page: qualifications, degrees or 
certifications, the profession, the author's background, other pages/documents the author has written

- I look at the URL of the site and, based on the domain (.com, .edu, .org, net, or others), use that information to help me determine whether or not the site has authority

- I do not examine the authority of a site

- I check with someone with knowledge of the site or topic (for example, library staff or a professor)

How do you evaluate the currency of a page and determine how current the information on the site is? Check all that apply.

- I do not understand what is meant by currency in this question

- I examine how frequently the site has been updated

- I look for a date on the site

- I do not believe it is possible to determine if the information returned by a search engine is current

- I do not evaluate the currency of a site

- I check with someone with knowledge of the site or topic (for example, library staff or a professor)

- I look for a copyright date

- I look at the dates of the references

- I check to see if all the links are still active (broken links will lead me to believe the site is not current)

How do you evaluate the purpose or bias of a website? Check all that apply.

- I do not understand what is meant by purpose in this question

- I determine whether or not the author of the page or the owner of the URL is trying to sell something

- I examine whether or not the purpose of the site is to promote a particular opinion or point of view

- I examine whether or not the site is spam, hoax, or joke

- I do not evaluate the purpose of a site

- I do not believe it is possible to determine the purpose of a page returned by a search engine

- I check with someone with knowledge of the site or topic (for example, library staff or a professor)

\section{Notes}

1. Association for College and Research Libraries, “Information Literacy Competency Standards for Higher Education" (Chicago: American Library Association, 2000).

2. J. Patrick Biddix, Chung Joo Chung, and Han Woo Park, "Convenience or Credibility? A Study of College Student Online Research Behaviors," The Internet and Higher Education 14, no. 3 (July 2011): 175-82; Kate Lawrence, “Today's College Students: Skimmers, Scanners and Efficiency-Seekers, " Information Services \& Use 35, no. 1-2 (2015): 89-93; Lea Currie, Frances Devlin, Judith Emde, and Kathryn Graves, "Undergraduate Search Strategies and Evaluation Criteria: Searching for Credible Sources," New Library World 111, no. 3/4 (2010): 113-24; Anne M. Fields, "Self-Efficacy and the First-Year University Student's Authority of Knowledge: An Exploratory Study," Journal of Academic Librarianship 31, no. 6 (2005): 539-45; Alison J. Head and Michael B. Eisenberg, "Truth Be Told: How College Students Evaluate and Use Information in the Digital Age, Project Information Literacy Progress Report," 2010, available online at http://projectinfolit. org/images/pdfs/pil_fall2010_survey_fullreport1.pdf [accessed 29 November 2016].

3. Joy Tillotson, "Web Site Evaluation: A Survey of Undergraduates," Online Information Review 26, no. 6 (Dec. 2002): 392-403. 
4. Biddix, Chung, and Park, "Convenience or Credibility?" 175-82; Lawrence, “Today's College Students," 91.

5. Head and Eisenberg, "How College Students Evaluate," 51.

6. Andrew J. Flanagin and Miriam J. Metzger, "Digital Media and Youth: Unparalleled Opportunity and Unprecedented Responsibility," in Digital Media, Youth, and Credibility, eds. Miriam J. Metzger and Andrew J. Flanagin (Cambridge, Mass.: MIT Press, 2008), 5-27; Melissa Gross and Don Latham, "Experiences with and Perceptions of Information: A Phenomenographic Study of First-Year College Students," Library Quarterly: Information, Community, Policy 81, no. 2 (2011): 161-86; Miriam J. Metzger, Andrew J. Flanagin, and Lara Zwarun, "College Student Web Use, Perceptions of Information Credibility, and Verification Behavior," Computers \& Education 41, no. 3 (2003): 271-90.

7. Ian Rowlands et al., "The Google Generation: The Information Behaviour of the Researcher of the Future," in Aslib Proceedings, vol. 60, no. 4 (2008): 290-310.

8. Deborah J. Grimes and Carl H. Boening, "Worries with the Web: A Look at Student Use of Web Resources," College \& Research Libraries 62, no. 1 (2001): 11-22.

9. Michael Lorenzen, "The Land of Confusion? High School Students and Their Use of the World Wide Web for Research," Research Strategies 18, no. 2 (2001): 151-63.

10. Tillotson, "Web Site Evaluation," 392-403.

11. Grimes and Boening, "Worries with the Web," 11-22; Head and Eisenberg, "How College Students Evaluate"; Brian Hilligoss and Soo Young Rieh, "Developing a Unifying Framework of Credibility Assessment: Construct, Heuristics, and Interaction in Context," Information Processing E Management 44, no. 4 (2008): 1467-84; Lorenzen, “The Land of Confusion?" 151-63.

12. Ananda Mitra, Jennifer Willyard, Carrie A. Platt, and Michael Parsons, "Exploring Web Usage and Selection Criteria Among Male and Female Students," Journal of Computer-Mediated Communication 10, no. 3 (Apr. 1, 2005).

13. Currie et al., "Undergraduate Search Strategies," 113-24; Lawrence, "Today's College Students," 92.

14. Nicholas Carr, The Shallows: What the Internet Is Doing to Our Brains (New York: W.W. Norton and Company, 2010); Grimes and Boening, "Worries with the Web," 11-22; Lorenzen, "The Land of Confusion?" 151-63; Arthur Taylor, "A Study of the Information Search Behaviour of the Millennial Generation," Information Research 17, no. 1 (2012); Peter Williams and Ian Rowlands, Information Behaviour of the Researcher of the Future: The Literature on Young People and Their Information Behavior: Work Package II (Bristol, United Kingdom: Joint Information Systems Committee, 2007), available online at www.webarchive.org.uk/wayback/archive/20140614113317/http://www. jisc.ac.uk/media/documents/programmes/reppres/ggworkpackageii.pdf [accessed 29 November 2016].

15. Miriam J. Metzger, Andrew J. Flanagin, and Ryan B. Medders, "Social and Heuristic Approaches to Credibility Evaluation Online," Journal of Communication 60, no. 3 (Sept. 2010): 413-39.

16. Head and Eisenberg, "How College Students Evaluate," 13, 40.

17. Metzger, Flanagin, and Zwarun, "College Student Web Use," 271-90.

18. Mitra et al., "Exploring Web Usage," 10.

19. Sook Lim and Nahyun Kwon, "Gender Differences in Information Behavior Concerning Wikipedia, an Unorthodox Information Source," Library \& Information Science Research 32, no. 3 (July 2010): 212-20; Jela Steinerová and Jaroslav Susol, “'Users' Information Behaviour: A Gender Perspective," Information Research 12, no. 3 (2007): 13.

20. Metzger, Flanagin, and Zwarun, "College Student Web Use," 271-90.

21. Lim and Kwon, "Gender Differences in Information Behavior," 212-30.

22. Deborah J. Fallows, "How Women and Men Use the Internet" (Pew Internet \& American Life Project, Dec. 28, 2005), available online at www.pewinternet.org/files/2005/12/PIP_Women_ and_Men_online.pdf [accessed 29 November 2016]; Steinerová and Susol, “Users' Information Behaviour," 13.

23. Tracey A. Burdick, "Success and Diversity in Information Seeking: Gender and the Information Search Styles Model," School Library Media Quarterly 25, no. 1 (1996): 19-26; Eszter Hargittai and Steven Shafer, "Differences in Actual and Perceived Online Skills: The Role of Gender*," Social Science Quarterly 87, no. 2 (2006): 432-48; Fallows, "How Women and Men Use the Internet"; Nai $\mathrm{Li}$ and Gill Kirkup, "Gender and Cultural Differences in Internet Use: A Study of China and the UK," Computers \& Education 48, no. 2 (Feb. 2007): 301-17.

24. Eszter Hargittai, "Beyond Logs and Surveys: In-Depth Measures of People's Web Use Skills," Journal of the American Society for Information Science and Technology 53, no. 14 (2002): 1239-44; Hargittai and Shafer, "Differences in Actual and Perceived Online Skills," 432-48; Ethelene Whitmire, "The Relationship between Undergraduates' Background Characteristics and College Experiences and Their Academic Library Use," College \& Research Libraries 62, no. 6 (2001): 528-40.

25. Burdick, "Success and Diversity in Information Seeking," 19-26. 
26. Teresa Yvonne Neely, Aspects of Information Literacy: A Sociological and Psychological Study (doctoral dissertation, University of Pittsburg, 2000).

27. Nahyun Kwon and Hana Song, "Personality Traits, Gender, and Information Competency among College Students," Malaysian Journal of Library \& Information Science 16, no. 1 (July 2011): 87-107.

28. Association for College and Research Libraries, "Information Literacy Competency Standards for Higher Education."

29. Neely, Aspects of Information Literacy.

30. Metzger, Flanagin, and Zwarun, "College Student Web Use," 271-90.

31. Burdick, "Success and Diversity in Information Seeking," 19-26.

32. Daniel Voyer and Susan D. Voyer, "Gender Differences in Scholastic Achievement: A MetaAnalysis," Psychological Bulletin 140, no. 4 (2014): 1174-1204.

33. Fallows, "How Women and Men Use the Internet"; Steinerová and Susol, "Users' Information Behaviour."

34. Herbert A. Simon, "Rational Choice and the Structure of the Environment," Psychological Review 63, no. 2 (1956): 129; Herbert A. Simon, "Rationality as Process and as Product of Thought," The American Economic Review 63, no. 2 (1978): 1-16; Amanda Spink et al., "What Is Enough? Satisficing Information Needs," Journal of Documentation 63, no. 1 (2007): 74-89.

35. Lynn Silipigni Connaway, Timothy J. Dickey, and Marie L. Radford, "'If It Is Too Inconvenient I'm Not Going after It': Convenience as a Critical Factor in Information-Seeking Behaviors," Library \& Information Science Research 33, no. 3 (2011): 179-90; Helen Georgas, "Google vs. the Library (Part III): Assessing the Quality of Sources Found by Undergraduates," portal: Libraries and the Academy 15, no. 1 (2015): 133-61.

36. Burdick, "Success and Diversity in Information Seeking," 26.

37. Anne M. Fields, “Women's Epistemological Development: Implications for Undergraduate Information Literacy Instruction," Research Strategies 18, no. 3 (2001): 227-38.

38. Ibid. 545.

39. Fields, "Self-Efficacy and the First-Year University Student's Authority of Knowledge,"

40. Katty Kay and Claire Shipman, “The Confidence Gap,” The Atlantic Monthly 313, no. 4 (2014): 56-66.

41. Constance A. Mellon, "Library Anxiety: A Grounded Theory and Its Development," College E Research Libraries 47, no. 2 (1986): 160-65.

42. Shelly Blundell and Frank Lambert, "Information Anxiety from the Undergraduate Student Perspective: A Pilot Study of Second-Semester Freshmen," Journal of Education for Library and Information Science 55, no. 4 (2014): 261-73.

43. Marc Meola, "Chucking the Checklist: A Contextual Approach to Teaching Undergraduates Web-Site Evaluation," portal: Libraries \& the Academy 4, no. 3 (2004): 331-44; Arthur Taylor and Heather A. Dalal, "Information Literacy Standards and the World Wide Web: Results from a Student Survey on Evaluation of Internet Information Sources," Information Research 19, no. 4 (2014).

44. Association for College and Research Libraries, "Framework for Information Literacy for Higher Education" (Chicago: American Library Association, 2015), available online at www.ala. org/acrl/standards/ilframework [accessed 29 November 2016]. 